\title{
Classification of hardened cement and lime mortar using short-wave infrared spectrometry data
}

\author{
Zohreh Zahiri', Debra F. Laefer ${ }^{2}$, and Aoife Gowen ${ }^{3}$
}

\begin{abstract}
This paper evaluated the feasibility of using spectrometry data in the short-wave infrared range $(1,300-2,200 \mathrm{~nm})$ to distinguish lime mortar and Type $\mathrm{S}$ cement mortar using 42 lab samples (21 lime-based, 21 cement-based) each $40 \times 40 \times 40 \mathrm{~mm}$ were created. A Partial Least Squares Discriminant Analysis model was developed using the mean spectra of 28 specimens as the calibration set. The results were tested on the mean spectra of the remaining 14 specimens as a validation set. The results showed that, spectrometry data were able to fully distinguish modern mortars (made with cement) from historic lime mortars with a $100 \%$ classification accuracy, which can be very useful in archaeological and architectural conservation applications. Specifically, being able to distinguish mortar composition in situ can provide critical information about the construction history of a structure, as well as to inform an appropriate intervention scheme when historic material needs to be repaired or replaced.
\end{abstract}

Keywords: hyperspectral, mortar, spectrometry, short-wave infrared, partial least square discriminant analysis

\section{Introduction}

Mortar joints may be repaired multiple times over a building's life-cycle depending upon exposure conditions, climate, and original materials. Differentiating repaired joints from original mortar is often difficult due to similarities in colour and texture after years of exposure, even when the composition may be quite distinctive. Documentation of such repairs may provide critical insights into the history of existing structures, especially if inappropriate materials (e.g. stiff cement based mortars) were used where more flexible lime-based mortar should be present. Identifying such differences can also help identify pathologies and their evolution. Hence, in this study, SWIR spectrometry data were used to see if mortar with cement was distinguishable from pure lime.

\section{Background}

Monitoring and documentation of historic buildings is important in conservation and management of masonry buildings and walls. X-ray diffraction (XRD) is a common technique used to obtain information about the

\footnotetext{
${ }^{1}$ PhD Candidate, Urban Modelling Group, School of Civil Engineering, University College Dublin, Belfield, Dublin 4, Ireland, zohreh.zahiri@ucdconnect.ie

${ }^{2}$ Professor of Urban Informatics, Center for Urban Science and Progress and Department of Civil and Urban Engineering, Tandon School of Engineering, New York University, 1 Metrotech Center, 19th Fl, Brooklyn, NY, 11201, USA, debra.laefer@ nyu.edu

${ }^{3}$ Associate Professor, School of Biosystems Engineering, University College Dublin, Belfield, Dublin 4, Ireland, aoife.gowen@ucd.ie
} 
composition of historic materials [1,2]. Often used to determine material composition and potential for reproduction of the original material for repair [3], XRD requires the destructive removal of material, thereby limiting its viability for historic structures and large projects.

Multispectral imaging has also been evaluated as a technique for classifying historic materials. Lerma [4] combined spectral and textural information [blue, green, red, and near-infrared (NIR) bands and three redtextural bands] to classify five different materials including cleaned cement mortar, flaking cement mortar, polished limestone, washed limestone, and dark limestone on the façade of Santos Juanés Church in Valencia, Spain [4]. The classification of mortar in this study was, however, limited to differentiating cleaned from dirty mortars. Lerma et al. [5] later demonstrated the benefit of multi-band data in the identification of different facade materials including rock, wood, and various cement mortars in the Virgin Basilica in Valencia, Spain. The classification of mortar in the latter was limited to mortars distinguishable by colour (ochre, white, and orange). Infrared thermography, a non-destructive technique in which heat emitted from a material which is converted into a thermal image using specialized detectors [6], has proven useful for detection of surface anomalies such as moisture [7] and delamination such as air pockets in concrete [8]. Despite success in mapping anomalies in historic buildings, thermography still lacks adequate quantifiable results for detailed material identification [3]. In contrast, spectroscopy has proven an accurate technique to study optical differences between materials. Spectroscopy is based on the electromagnetic radiation reflected or absorbed by a sample, which is a function of wavelength, chemical-mineralogical surface properties, and physical parameters [9]. In a comparative study, differential thermogravimetry (which measures changes materials' physical properties with temperature) and infrared spectroscopy in the range of $400-5200 \mathrm{~cm}^{-1}$ were used to characterize historical mortars (typical lime, cements, with crushed brick, with portlandite, with gypsum, and with modern cements) from St. John Church, in Tartu, Estonia [10]. The infrared spectra of mortars showed hydraulic peaks at $1,520 \mathrm{~cm}^{-1}$ and $\mathrm{CO}_{2}$ peaks at $670 \mathrm{~cm}^{-1}$. Similarly, Riccardia et al. [11] differentiated original medieval mortar from later 16th century mortar using thermal analysis [11] and showed that weight loss as a function of temperature differed in Roman mortar, medieval mortar, and Renaissance mortars. More calcite was also observed for Roman and medieval mortars. Spectrometry has also been used to detect mortar damage. For example, Micro-Raman spectroscopy was used to quantify calcium carbonate formation at different depths in lime mortar. Notably, this was achieved without destroying the samples [12]. Similarly, infrared spectrometry $\left(400-2,000 \mathrm{~cm}^{-1}\right)$ was employed to study anthropogenic calcite pollution in mortar and plaster on samples obtained from archaeological sites across Israel [13]. Additionally, Micro-Raman spectrometry (in the range of $200-1,200 \mathrm{~cm}^{-1}$ ) has been used to study the chemical composition and phase distribution in cementitious materials and cement stone samples taken from façade elements of four historic Swiss buildings [14]. Despite promising initial results, Raman microscopic imaging is time consuming and limited to imaging samples in the laboratory.

Pioneering work in establishing a library of identifiable urban materials (e.g. stone, brick, concrete, and roof tiles) through imaging spectrometry was introduced by Kotthaus et al. [15]. Distinctive absorption features were detected for cement and concrete materials using hyperspectral data in visible and SWIR range, but with little consideration for variations within a class of materials. As such, there has yet to be a non-destructive method 
able to identify reliably mortar types. The ability to do this will enable significantly improved documentation and intervention activities for the conservation of historic structures. Thus, the study herein will explore a method to classify different mortar types.

\section{Materials and methods}

\subsection{Sample preparation}

The study included two distinctive mortar mixes: lime putty representing a historic mix and Type S [16] representing a strong modern mix appropriate only for modern masonry units. The lime putty was a commercial product (Cornish Lime Co. Ltd, UK) delivered pre-hydrated with the consistency of cream. After mixing the lime putty with sand, only a small amount of water was added until good workability was achieved (Table 1). The Type S mortar was made of one unit of cement (Normal Type 1, Irish Portland cement) and half a unit of hydraulic lime (The Lime Store, Ireland) mixed in the laboratory in a small countertop mixer. Water was gradually added to the lime, cement, and sand in the mixing bowl until the mix obtained an appropriate workability. The mortar mixes were cured at room temperature $\left(18^{\circ} \mathrm{C}\right)$ in cubes of approximately $40 \times 40 \times 40 \mathrm{~mm}$ (Fig. 1).

Table 1. Mortar composition

\begin{tabular}{|c|c|c|c|c|}
\hline Mortar Type & Sand & Water & Cement & Lime \\
\hline Type S & 3 & 0.8 & 1 & 0.5 \\
\hline Fat Lime & 2.5 & 0.15 & 0 & 1 \\
\hline
\end{tabular}

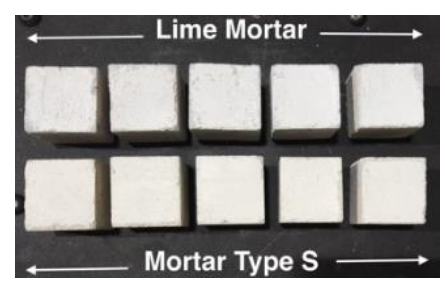

Figure 1. Red-Green-Blue (RGB) image of mortar samples across the two mortar classes

\subsection{Equipment (SWIR Spectrometry)}

A Perkin Elmer Lambda 900 UV/VIS/NIR Spectrometer was used to scan the samples. This spectrometer has a double-beam, double monochromator ratio recording system with pre-aligned tungsten-halogen and deuterium lamps (Fig. 2). The wavelength range of this instrument is $175-3,300 \mathrm{~nm}$, with an accuracy of $0.08 \mathrm{~nm}$ in the visible ultra-violet region and $0.3 \mathrm{~nm}$ in the NIR region. In this study, the device was set to the Short-wavelength Infrared (SWIR) range $(1,300-2,200 \mathrm{~nm})$ with a spectral resolution of $5 \mathrm{~nm}$. This range was selected based on previous testing $[17,18]$ showing that many rock-forming minerals such as carbonates, clays, micas, oxides, and hydroxides demonstrate diagnostic absorption features in the SWIR range. Calibration of the equipment with a $100 \%$ reflectance reference showed zero absorption in all wavelengths. Subsequently, each mortar sample was placed individually into the spectrometer, which was closed during scanning to prevent room illumination interference effects. A minimum of five spectra were collected from different parts of each sample's surface. 


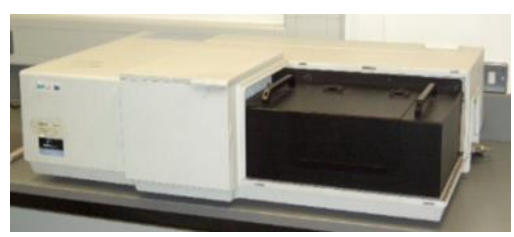

Figure 2. Spot spectrometry testing equipment: Perkin Elmer Lambda 900 UV/VIS/NIR Spectrometer

Due to the samples' morphology that could result in non-uniform illumination, spectra corrections were necessary. Applying a Standard Normal Variate (SNV) pre-treatment, the offset and multiplicative effects were removed from each spectrum through centering and scaling each by its own standard deviation [19]. Corrections were also needed to address bad pixels with a noise level or responsivity outside of a pre-established, acceptable limit [20]. Noise may have arisen from the line sensors, the push-broom scanning operation [21], or a failure of a detector element in the charge-coupled device. To correct for this, bad pixels were replaced with interpolated values using a Savitzky-Golay smoothing filter with the 7 nearest values: 3 longer and 3 shorter wavelengths on the spectral curve [22]. After this, the mean spectrum was calculated for each sample for further analysis.

\subsection{Data Analysis}

Data analysis was conducted in Matlab (release R2014b) incorporating functions from the Image Processing and Statistics toolboxes and additional functions written by the authors. Partial Least Squares Discriminant Analysis (PLSDA) [23] was used to classify the samples. PLSDA is a supervised classification technique used to find the fundamental relationship between two matrices $\mathrm{X}$ and $\mathrm{Y}$, where $\mathrm{X}$ is the measured information for each sample (spectra of the samples), and $\mathrm{Y}$ is a column vector defining class membership for each sample. In this study, a PLSDA model was developed to classify lime mortar and Type S mortar. A total of 42 mortar samples (21 lime and 21 Type S mortar) were scanned, and the mean spectrum of each sample was calculated. In the classification model, two-thirds of each mortar class (14 samples from each mortar class) were randomly selected (using the randomperm function in Matlab) for the calibration set, and the rest ( 7 samples from each class) were kept for validation, resulting in 28 calibration and 14 validation samples. The spectra of the calibration and validation sets contained $\mathrm{X}$ matrixes in the model, and the $\mathrm{Y}$ variables described the class membership. In other words, the Y variable was 1 for "in class" samples and 0 for "out of class" samples. The process was repeated in its entirety for the second model with a second random sample to test the applicability of the method.

\section{Results}

The mean spectra of the mortar classes are displayed in Fig. 3. The initially noisy spectra (Fig. 3a) became smoother after applying the Savitzky-Golay smoothing filter (Fig. 3b), while the offset in absorbance among spectra was removed after applying SNV pre-treatment (Fig. 3c). One main absorption feature was observed at $1,930 \mathrm{~nm}$ in both mortar classes, and another absorption feature appeared at $1,445 \mathrm{~nm}$ for the Type $\mathrm{S}$ mortar and 
slightly for the lime (Fig. 3). Also, for the Type S mortar, the amount of absorption at the 1,930nm wavelength was much larger, especially after applying SNV and plotting the mean spectra (1.92 vs. $0.83 \mathrm{~cm}-1)$ [Fig. 3d].

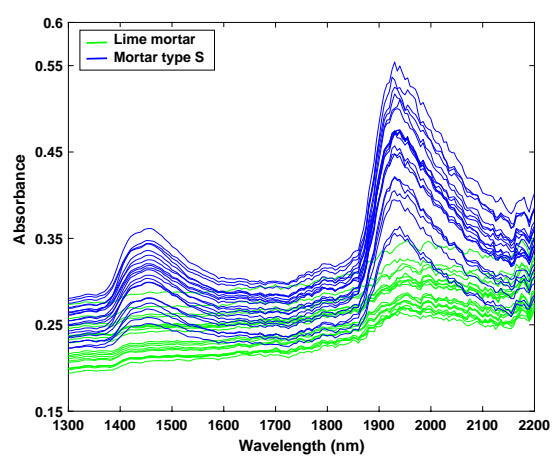

a) Raw spectra of samples

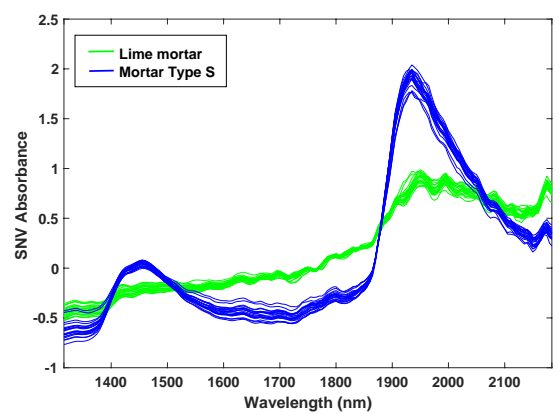

c) Spectra of samples after smoothing and SNV pretreatment

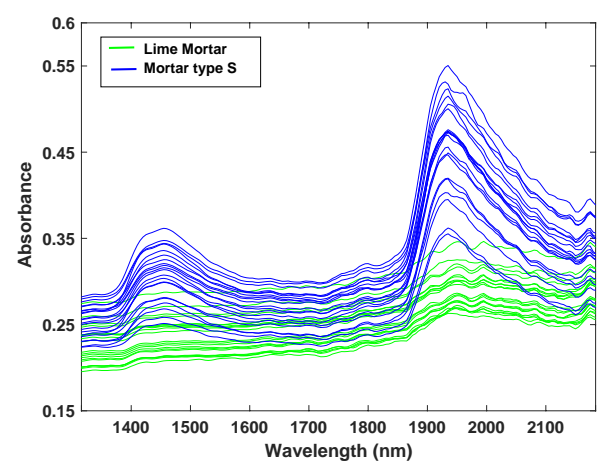

b) Spectra of samples after smoothing filter

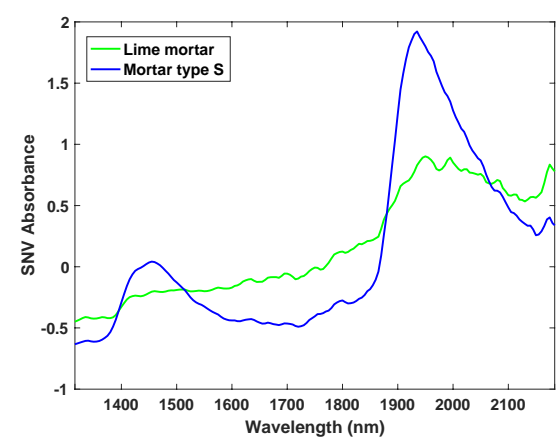

d) Mean spectra of mortar classes after smoothing and SNV pretreatment

Figure 3. Spectra of type $S$ vs. lime mortar before and after applying pre-treatments

A PLSDA model was created on the calibration set of lime and Type S mortar samples, for which the misclassification error for first 20 latent variables was plotted (Fig. 4). Across these, the misclassification error decreased sharply from $53 \%$ in $L V=1$ to $0 \%$ in $L V=2$. Hence only the first 2 latent variables were considered, and a 100\% correct classification rate (CCR) was achieved for both the calibration and validation sets [Fig. 5] with and without pre-treatment in both random samples (Table 2). The high CCR may be attributable to the distinctive absorption amounts in the $1,445 \mathrm{~nm}$ and $1,930 \mathrm{~nm}$ wavelengths (Fig. 3). The regression vectors of the mortar classes at $\mathrm{LV}=2$ demonstrated that $1,930 \mathrm{~nm}$ and $1,445 \mathrm{~nm}$ were possible classification wavelengths for these two mortar classes, as they had the largest regression coefficients among the vectors (Fig. 6). These two wavelengths exactly matched the absorption features that appeared in the mean spectra of the mortar classes (Fig. 3). 


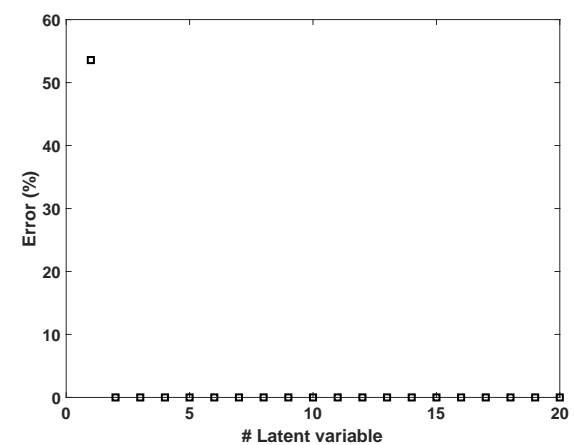

Figure 4. Misclassification error for the first 20 latent variables

Table 2. Results of classification using different samples (with and without pre-treatment)

\begin{tabular}{|c|c|c|c|c|}
\hline \multirow{2}{*}{ Data type } & \multicolumn{2}{|c|}{ Sample selection (Random1) } & \multicolumn{2}{c|}{ Sample selection (Random2) } \\
\cline { 2 - 5 } & \#LV & CCR \% & \#LV & CCR\% \\
\hline No pre-treatment & 2 & $100 \%$ & 2 & $100 \%$ \\
\hline SNV pre-treatment & 2 & $100 \%$ & 2 & $100 \%$ \\
\hline Both SNV and SG & 2 & $100 \%$ & 2 & $100 \%$ \\
\hline
\end{tabular}
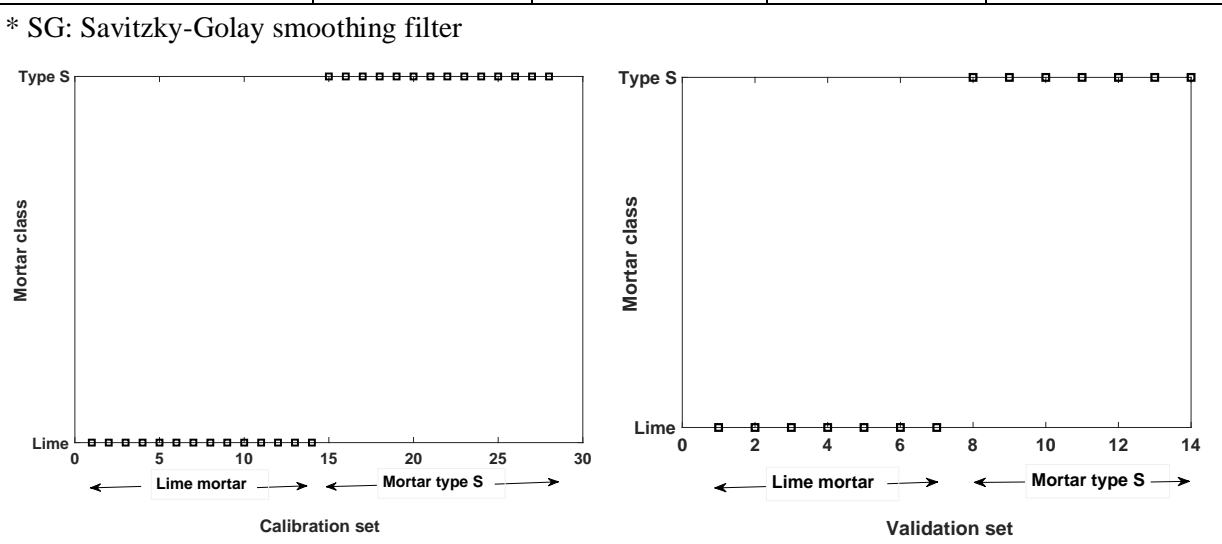

Figure 5. Results of classification on calibration and validation sets of mortar samples
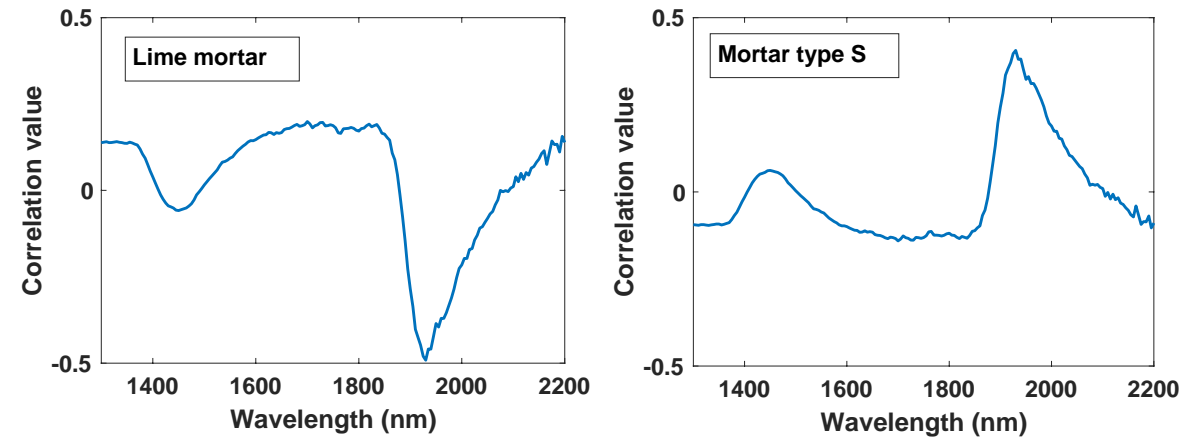

Figure 6. Regression vector of mortar classes in $L V=2$

\section{Discussion}

Previous SWIR spectroscopy studies of concrete and cementitious materials have observed absorption features in the spectra of concrete near the same wavelengths as those found herein: one small feature around 1,410nm, the signature of iron oxides or absorption at other $\mathrm{H}_{2} \mathrm{O}$ related bands, and one large feature around 1,940- 
1,970nm, indicating the $\mathrm{H}_{2} \mathrm{O}$ related absorption of gypsum [15]. At the conclusion of this study, one of each of the mortar samples was further scanned with a Hyspex 320 hyperspectral camera. Although the two detectable absorption peaks appeared slightly shifted $(1,410 \mathrm{~nm}$ and $1,915 \mathrm{~nm}$ vs. $1,445 \mathrm{~nm}$ and $1,930 \mathrm{~nm})$, they showed similar trends, except that the smaller peak was now more clearly visible for the lime mortar (Fig. 7). While conducted on a relatively limited data set, the results suggest the feasibility of using hyperspectral imaging for distinguishing mortar types.

Despite their similarities, each of these spectrometry techniques has advantages and drawbacks. Spot spectrometry requires removing original materials for laboratory-based testing which is undesirable for historic buildings, while hyperspectral cameras can be used in the field and can scan a building from an offset of several meters with minimal intervention into original materials. Due to spot spectrometry's time consuming process, only a few spectra were collected from each sample's area while in hyperspectral imaging the whole area of the sample can be scanned within a few minutes, providing more complete information about the samples. While hyperspectral imaging can provide more comprehensive information in a short time, the data are influenced by atmospheric and lighting conditions. However, with calibration and atmospheric corrections, imaging spectrometry can be used as a superior technique for non-destructive assessing historic buildings and materials in field. To further investigate this hypothesis, additional testing must be undertaken: field testing under various exposure and lighting conditions; mortars with the same binder but different types and gradation of aggregate; and mortar ranges that are more closely related (e.g. Type $\mathrm{S}$ vs Type $\mathrm{N}$ or Type $\mathrm{K}$ vs Type $\mathrm{O}$ ).

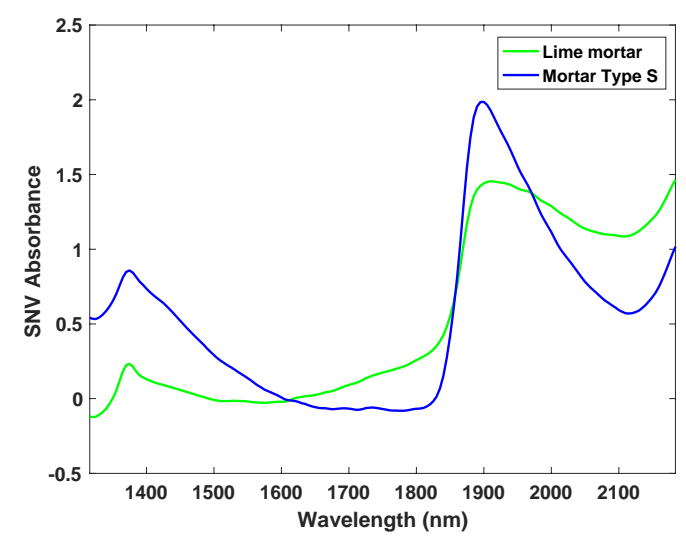

Figure 7. Reflectance spectra of mortar types

\section{Conclusions}

In this study a PLSDA classification model was built based on the spectra of mortar samples from two mortar types: lime and Type $\mathrm{S}$ (with a mostly cement binder). The spectra were collected within the short-wave infrared range 1,300-2,200nm and from multiple parts of each sample. The classification model was built on a calibration set of 28 samples across both mortar types and resulted in $100 \%$ CCR on the 14 validation samples. The results showed that, despite very similar surface shape (colour and texture), mortar classes can be distinguished by their spectra, thus affirming the potential usefulness of this technique for documentation in heritage conservation. 


\section{Acknowledgments}

The authors wish to thank Dr. Hugh Byrne and Luke O'Neill from Dublin Institute of Technology as well as Mr. Derek Holmes and Mr. John Ryan from University College Dublin for their support and assistance in conducting the experimental parts of the study. Funding for this work was provided by New York University's Center for Urban Science and Progress. Dr. Gowen acknowledges funding from the European Research Council (ERC) under the starting grant programme ERC-2013-StG call—Proposal No. 335508—BioWater.

\section{References}

[1] Abdelrazig BEI, Sharp JH, El-Jazairi B (1988) The chemical composition of mortars made from magnesiaphosphate cement. Cement and concrete research. 18(3):415-425.

[2] Charola AE, Dupas M, Sheryll RP, et al (1986) Characterization of ancient mortars: chemical and instrumental methods. In: Scientific methodologies applied to works of art. Proceedings of the symposium, Montedison Progetto Cultura, pp. 228-233.

[3] Jallad KN, Santhanam M, Cohen MD, et al (2001) Chemical mapping of thaumasite formed in sulfate-attacked cement mortar using near-infrared Raman imaging microscopy. Cement and Concrete Research 31(6):935-958.

[4] Lerma JL, Ruiz LÁ, Buchón F (2000) Application of spectral and textural classifications to recognize materials and damages on historic building facades. International Archives of Photogrammetry and Remote Sensing XXXIII(B5):480-484.

[5] Lerma JL (2001) Multiband versus multispectral supervised classification of architectural images. Photogrammetric Record 17(97):89-101. doi:10.1111/0031-868X.00169.

[6] Hussain A, Akhtar S (2017) Review of Non-Destructive Tests for Evaluation of Historic Masonry and Concrete Structures. Arabian Journal for Science and Engineering 42(3):925-940.

[7] Barreira E, Freitas VPde (2007) Evaluation of building materials using infrared thermography. Construction and Building Materials 21(1):218-224.

[8] Zhu Z, Brilakis I (2008) Detecting air pockets for architectural concrete quality assessment using visual sensing. Journal of Information Technology in Construction 13:86-102.

[9] Hermann R, Onkelinx C (1986) Quantities and units in clinical chemistry: Nebulizer and flame properties in flame emission and absorption spectrometry. Pure and Applied Chemistry 58(12):1737-1742.

[10] Paama L, Pitkanen I, Ronkkomaki H, et al 1998. Thermal and infrared spectroscopic characterization of historical mortars. Thermochimica Acta. 320(1-2):127-133.

[11] Riccardi MP, Duminuco P, Tomasi C, et al (1998) Thermal, microscopic and X-ray diffraction studies on some ancient mortars. Thermochimica Acta 321(1-2):207-214.

[12] Martinez-Ramirez S, Sanchez-Cortes S, Garcia-Ramos JV, et al (2003) Micro-Raman spectroscopy applied to depth profiles of carbonates formed in lime mortar. Cement and concrete Research 33(12):2063-2068.

[13] Chu V, Regev L, Weiner S, et al (2008) Differentiating between anthropogenic calcite in plaster, ash and natural calcite using infrared spectroscopy: implications in archaeology. J Arch Sci 35(4):905-911.

[14] Schmid T, Dariz P (2013) Determination and imaging of binder remnant and aggregates in historic cement stone by Raman microscopy. Journal of Raman Spectroscopy 44(6):882-891.

[15] Kotthaus S, Smith TE, Wooster MJ, et al (2014) Derivation of an urban materials spectral library through emittance and reflectance spectroscopy. ISPRS Journal of Photogrammetry and Remote Sensing 94:194-212. doi: 10.1016/j.isprsjprs.2014.05.005

[16] ASTM International (2014) Standard Specification for Mortar for Unit Masonry C270-14a. doi: 10.1520/C0270$14 \mathrm{~A}$

[17] Hunt GR, Salisbury JW (1976) Visible and Near-Infrared Spectra of Minerals and Rocks: XI. Sedimentary Rocks. Modern Geology 5:211-17.

[18] Clark RN, King TVV, Klejwa M, et al (1990) High Spectral Resolution Reflectance Spectroscopy of Minerals. Journal of Geophysical Research: Solid Earth 95(B8):12653-80.

[19] Esquerre C, Gowen AA, Burger J, et al (2012) Suppressing sample morphology effects in near infrared spectral imaging using chemometric data pre-treatments. Chemometrics and Intelligent Laboratory Systems 117:129-137. doi:10.1016/j.chemolab.2012.02.006. 
[20] Kieffer HH (1996) Detection and correction of bad pixels in hyperspectral sensors. In: Shen S (ed) Proceedings Volume 2821 SPIE's 1996 International Symposium on Optical Science, Engineering, and Instrumentation, SPIE, 93-108. doi:10.1117/12.257162.

[21] Nieke J, Schläpfer D, Dell'Endice F, et al (2008) Uniformity of Imaging Spectrometry Data Products. IEEE Transaction on Geoscience and Remote Sensing 46(10):3326-3336.

[22] Kurz TH, Buckley SJ, Howell JA (2013) Close-range hyperspectral imaging for geological field studies: workflow and methods. International Journal of Remote Sensing 34(5):1798-1822. doi:10.1080/01431161.2012.727039.

[23] Geladi P, Kowalski BR (1986) Partial least-squares regression: A tutorial. Analytica Chimica Acta 185:1-17. doi:10.1016/0003-2670(86)80028-9. 